\title{
Familial Essential Thrombocytemia : 6 cases from a mono-institutional series.
}

Vincenzo Accurso ${ }^{1}$, Marco Santoro ${ }^{2}$, Salvatrice Mancuso ${ }^{1}$, Giorgia Vajana ${ }^{3}$, Riccardo Tomasello $^{4}$, Cristina Rotolo ${ }^{4}$, Giulia Camarda ${ }^{4}$, Marta Mattana ${ }^{4}$, and Sergio Siragusa ${ }^{4}$

${ }^{1}$ Azienda Ospedaliera Universitaria Policlinico

${ }^{2}$ University Hospital Policlinico Paolo Giaccone

${ }^{3}$ Policlinico di Palermo

${ }^{4}$ Policlinic of Palermo

July 22, 2021

\begin{abstract}
Essential thrombocythemia is chronic myeloproliferative neoplasia, as defined by WHO in 2016, with the best prognosis. A small percentage of ET cases can be considered Familial ET. In this report we describe 6 cases of Familial ET, evaluating the heterogeneity of the mutational state and the clinical presentation.
\end{abstract}

\section{Hosted file}

Familial Essential Thrombocythemia_draf_vincenzo.doc available at https://authorea.com/ users/427040/articles/531349-familial-essential-thrombocytemia-6-cases-from-a-monoinstitutional-series 